\title{
Comparative Study of Moringa oleifera with Moringa peregrine Seed oil using GC-MS and its Antimicrobial Activity against Helicobacter pylori
}

\author{
MUAZZAM SHERIFF MAQBUL ${ }^{1}$, ALI MOHAMED ALSHABI ${ }^{2}$, AEJAZ ABDULLATIF KHAN ${ }^{3}$, \\ S.M. SHAKEEL IQUBAL ${ }^{3 *}$, IBRAHIM AHMED SHAIKH ${ }^{4}$, TASNEEM MOHAMMED ${ }^{3}$, MOHAMMED \\ SHAFIUDDIN HABEEB ${ }^{4}$, YUMNA ABDULMALEK BOKHARI ${ }^{5}$, KAYAMKANI ABEDULLA KHAN ${ }^{6}$ \\ and MOHAMMED SHAHID HUSSAIN ${ }^{7}$
}

${ }^{1}$ Faculty of Microbiology and Immunology, Ibn Sina National College of Medical Sciences, Al-Mahjar Street, 31906, Jeddah 21418, Kingdom of Saudi Arabia.

2Department of Clinical Pharmacy, College of Pharmacy, Najran University, Najran, Saudi Arabia. ${ }^{3}$ Department of General Science, Ibn Sina National College of Medical Sciences, Al-Mahajar Street, 31906, Jeddah 21418, Kingdom of Saudi Arabia.

${ }^{4}$ Department of Pharmacology, College of Pharmacy, Najran University, Najran, Saudi Arabia.

${ }^{5}$ Medicine Program, Ibn Sina National College of Medical Sciences, Al-Mahjar Street, 31906, Jeddah 21418, Kingdom of Saudi Arabia.

${ }^{6}$ Department of Clinical Pharmacy \& Pharmacology, Ibn Sina National College for Medical Studies, Jeddah, Kingdom of Saudi Arabia.

${ }^{7}$ Department of Orthodontics, B.D.S., M.D.S., Private Practice, Kingdom of Sudi Arabia.

${ }^{*}$ Corresponding author E-mail: shakeeliqubal@gmail.com

http://dx.doi.org/10.13005/ojc/360318

(Received: May 13, 2020; Accepted: June 14, 2020)

\section{ABSTRACT}

The World Health Organisation (WHO) has stated that about fifty percent of the world population is inflicted with the gastro-duodenal diseases due to contamination food and water where antibiotics are the only choice of treatment. The abundant use of antibiotics also has resulted in the emergence of mutant multi drug resistant organisms. The starting point of a revolution concerning the concepts for the management of gastro-duodenal diseases was initiated upon the discovery of Gram-negative helical shaped bacterium known as Helicobacter pylori in the year 1982. In this study Polymerase chain reaction technique was used to detect its 16S rRNA gene sequence analysis unambiguously. This study is a small effort to resurrect the ancient phyto-pharmaceutical substances to treat such infections by comparing the antimicrobial efficacy alongside bioactive composition analysis of the dried seed oils of Moringa oleifera from Indian origin and Moringa peregrine from Egyptian origin. The phenolic content in these seed oils almost serves as the potential antimicrobial effect towards combating the pathogens and preventing the infection to curb the diseases. The biochemical components present in the dried seed oils of $M$. oleifera and $M$. peregrina were determined by GC-MS analysis. The antimicrobial efficacy of the seed oils were studied using the standard antibiotic assay technique which determined that the sensitivity of the bacterium towards both the seed oil was excellent when compared to that of the eight standard chemical antibiotics used for the comparative study. The minimal concentration value of these seeds shown promising results to inhibit or completely eradicate the bacterium when compared to the values of the eight standard chemical antibiotics used for the comparative study.

Keywords: Moringa Seed oil, Helicobacter pylori, Moringa oleifera, Moringa peregrine, PCR, GC-MS, Antimicrobial activity.

This is an Open Access article licensed under a Creative Commons license: Attribution 4.0 International (CC- BY). Published by Oriental Scientific Publishing Company @ 2018 


\section{INTRODUCTION}

Helicobacter pylori causes duodenal ulcers, gastritis and plays a vital role in the development of gastric cancer. According to $\mathrm{WHO}$, about fifty percent of the world population is suffering with the gastro-duodenal diseases, where antibiotics are the only choice of treatment. ${ }^{1-2}$ However, irrational use of antibiotics results in emergence of mutant multi drug resistant organisms. ${ }^{3}$ Though the gastrointestinal pathogens such as E. coli, Salmonella, Shigella or Vibrio contribute to the gastroduodenal diseases but the starting point of a revolution concerning the concepts for the management of gastro-duodenal diseases was initiated upon the discovery of the Gram-negative helical shaped bacterium known as $H$. pylori in 1982, which is now well accepted to be the causative agent for the most common stomach gastritis diseases and peptic ulcer disease..$^{4-6}$ H. pylori was considered as Campylobacter pylori before its discovery due to its identical characteristics. ${ }^{4,7}$ Later it was differentiated from Campylobacter pylori by means of Polymerase chain reaction (PCR) technique to detect its 16S rRNA gene sequence analysis unambiguously. ${ }^{8-9}$ Since then the application of PCR technique for the identification of $H$. pylorihas become mandatory. This bacterium colonizes the mucus layer and epithelial mucus of the stomach to infect the host for the lifetime by damaging the tissues in the epithelial cells by vacuolation due to the production of a cytotoxin known as vacuolating cytotoxin. $H$. pylori is classified as a Class (I) carcinogen for gastric cancer and gastric Mucosa Associated Lymphoid Tissue (MALT) lymphoma, as this bacterium is the principle cause of chronic active gastritis, stomach and peptic ulceration. ${ }^{1-2,10}$ The $H$. pylori bacterium commonly harbors the stomach of the humans and the endoscopic biopsy gastric juice is the preferred specimen for the study. The In vitro culturing of $H$. pylori is a tedious task as the helical shape of the bacterium tends to change its shape to coccoidal form in the adverse environment where there is a lack of nutrients and hence proper precautions are needed to maintain steady supply of the nutrients ${ }^{9}$. The preferred supplement of choice for the culture of $H$. pylori In vitro is blood incorporated medium. This bacterium shows strong positive result for the urease enzymatic test which is a key marker for the identification of this bacterium species from others. , $^{911-12}$
The natural oil extracts from herbal sources were used in ancient times for the treatment of many bacteriological diseases and has proved to be an effective antimicrobial substances. ${ }^{3,13-14}$ The phenolic content in these seed oils serves as the potential antimicrobial effect towards combating the pathogens and preventing the infection to curb the diseases. ${ }^{13-15} \mathrm{~A}$ south Asian subcontinent tree named as $M$. oleifera belonging to the Moringaceae family contains abundant source of flavonoids, phenols, phenolic glycosides, saponins and cyanogenic glycosides which serves as an excellent antimicrobial resource for the treatment of many ailments. ${ }^{16}$ $M$. oleifera is spread across the southern parts of India especially in Tamil Nadu. The leaves, fruit, pods and flowers of the tree were consumed as a traditional edible food substances especially in the southern parts of India which was used for the bowel related disorders and for proper bowel function. ${ }^{16-}$ 18 The studies on $M$. oleifera fractioned seeds by using $n$-hexane and $\beta$-amyrin - $\beta$-sitosterol-3-O$D$-glucoside and apigenin has proven to contain an excellent antimicrobial properties when tested against various bacterial and fungal pathogens. ${ }^{16,19}$ Similarly, M. peregrina was used since ancient times in the Egypt due to its rich phytochemical composition and antimicrobial properties. ${ }^{20}$ M. peregrine seed oil also known as ben oil is stated in the Biblical literature about its medicinal values..$^{20-22}$ The Indian culture and Egyptian culture has crafted the use of these seeds oils for their routine food habits due to its rich antioxidant biochemical properties and antimicrobial activities especially for the treatment of bowel related syndromes. ${ }^{20-23}$

This investigation was to compare the biochemical components using GC-MS analysis18 of the seed oils of the $M$. oleifera with $M$. peregrine and to evaluate its efficacy as a potential antimicrobial substance against the clinical specimens of $H$. pylori is suffering from gastro-duodenal disease inflicted patients by applying standard microbiological antibiotic assay with PCR identification of the bacterium.

\section{MATERIAL AND METHODS}

\section{Reagents}

Moringa oleifera and $M$. peregrine dried seeds were procured from Jeddah local market. Endoscopic biopsy gastric juice sample was obtained from Al Jedaani Hospital, Jeddah. All the chemicals 
used during this research were of analytical grade. Double beam UV-Vis spectrophotometer, Perkin Elmer Clarus 600 GC System, Gel electrophoresis, Gene Labserve white mini thermal cycler PCR model No. IG-25, standard antibiotics and standard Hi Media were used.

\section{Preparation of the ethanol extract from the seeds}

Moringa oleifera and M. peregrine dried seeds were collected. The dried seeds were powdered separately using the mechanical crusher. Soxhlet extraction was performed at $90^{\circ} \mathrm{C}$ for $16 \mathrm{~h}$ for both the dried seed powders separately. The dried seed powder weighing $250 \mathrm{~g}$ were extracted exhaustically with $500 \mathrm{~mL}$ of $70 \%$ ethanol from this procedure of extraction. Kupchan's partitioning technique was employed to get the extracts of methanol, ethyl acetate, hexane and chloroform by fractionating the crude ethanol extract obtained from the evaporated polar extract at low pressure. Corresponding semi solid extracts were obtained by drying the each obtained fractionated extracts by evaporation technique in a fuming hood. ${ }^{20-24}$

\section{Bioactive chemical composition of the seeds extract}

The following standard techniques were employed for the qualitative analysis of seeds from the ethanol extraction method to enumerate its bioactive chemical composition.

\section{Folin-Ciocalteu reagent technique}

The Total Phenol Content (TPC) present in the seeds was determined by employing FolinCiocalteu reagent techniques for the obtained methanol, ethyl acetate, hexane and chloroform by fractionating the crude ethanol extract. ${ }^{13}$ The reference standard used for this test was $70 \mu \mathrm{g} / \mathrm{mL}$ of gallic acid. The seeds extract of $100 \mu \mathrm{g} / \mathrm{mL}$ with a volume of 0.5 $\mathrm{mL}$ with $1.5 \mathrm{~mL}$ of Folin-Ciocalteu reagent and was diluted with DI water for the proportion of 1:10 sodium carbonate solution with a volume of $3 \mathrm{~mL}$ used as the neutralizer. The reaction mixture was observed for color development with intermittent shaking at room temperature for 30 minute. The double beam UV-Vis spectroscopy (UV Analyst-CT 8200) using fixed wavelength of $765 \mathrm{~nm}$ to measure the $O D$ of the resulting blue color. From the obtained linear regression equation (LRE) the standard plot of gallic acid determined the TPC and TPC content expressed as $\mathrm{mg} / \mathrm{gr}$ gallic acid equivalent (GAE) of dried seed with calculated mean of $S D(n=3) \cdot{ }^{24-26}$

\section{Aluminum chloride colorimetric technique}

The Total Flavonoid Content (TFC) present in the seed oils was determined by employing colorimetric technique with the extracts of the seeds. ${ }^{13}$ The standard constituent used in this technique was $10 \mathrm{mg}$ of quercetin diluted to the concentrations of $20,40,60,80$ and $100 \mu \mathrm{g} / \mathrm{ml}$ by dissolving in $80 \%$ ethanol. Similarly, the set dilutions for the of seeds extracts were prepared. The test is performed by adding $0.1 \mathrm{~mL}$ of $10 \%$ aluminum chloride, with $0.1 \mathrm{~mL}$ of $1 \mathrm{~mol} / \mathrm{L}$ potassium acetate and $2.8 \mathrm{~mL}$ of distilled water to the $0.5 \mathrm{~mL}$ of each prepared dilutions separately in test tubes. This mixture was then treated with $1.5 \mathrm{~mL}$ of $95 \%$ ethanol and incubated at room temperature for $30 \mathrm{~min}$ to observe the reaction. Using the double beam UV-Vis spectrophotometer at $415 \mathrm{~nm}$ the $\mathrm{OD}$ of the reaction was measured against blank solution which contains all reagents with the exceptional of aluminium chloride removed using distilled water with the same equal quantity. The LRE obtained from the quercetin calibration was used for the calculation of TFC in $\mathrm{mg} / \mathrm{g}$ using mean SD $(\mathrm{n}=3)$ which corresponds to the quercetin equivalent of the dry extract. $13,17,24-26$

\section{DPPH -2,2-diphenyl-1-picrylhydrazyl radical technique}

The different concentrations of the seeds extract for the analysis of the free radical scavenging activity was assayed by employing the standard DPPH radical scavenging technique. The ascorbic acid was used as the standard reagent for this technique. The different concentrations of the seeds extracts and the standard ascorbic acid were prepared by serial dilution methods with a set of concentrations of $10,25,50,100$ and $200 \mu \mathrm{g} /$ $\mathrm{mL}$. The DPPH radical solution of $1.0 \mathrm{mmol} / \mathrm{L}$ was added to the $1 \mathrm{ml}$ of all the concentrations with the double volume of $2 \mathrm{~mL}$ separately and incubated for about $30 \mathrm{~min}$ in room temperature in dark condition for the reaction to be observed. By employing the same procedure a working blank was prepared for the analysis excepting ascorbic acid replaced by equal amount of distilled water. The UV-Vis spectrophotometer used employed to measure the decrease in absorbance at $517 \mathrm{~nm}$. The percentage of radical scavenging activity of tested extract of the seeds and the standard control ascorbic acid concentration required to scavenge $50 \%$ of DPPH free radical was determined from the percent inhibitions against the respective concentration. . $^{13,17,24-26}$ 


\section{Scavenging assay of the seeds extract}

The scavenging assay of the seeds extract was performed by employing the standard hydrogen peroxide scavenging assay where $40 \mathrm{mmol} / \mathrm{L}$ of $\mathrm{H}_{2} \mathrm{O}_{2}$ solution prepared with $50 \mathrm{mmol} / \mathrm{L}$ of $\mathrm{PO}_{4}^{-3}$ buffer solution measured at $230 \mathrm{~nm}$. The various concentration $5,10,25,100 \mathrm{ug} / \mathrm{mL}$ extracts of the seeds and the ascorbic acid solution were prepared. To each $1 \mathrm{~mL}$ concentration of the dilutions $2 \mathrm{~mL}$ of the $\mathrm{H}_{2} \mathrm{O}_{2}$ solution were added separately in the test tubes and incubated at room temperature for 30 min to determine the absorbance of assay mixture against $\mathrm{PO}_{4}^{-3}$ buffer excepting $\mathrm{H}_{2} \mathrm{O}_{2}$ solution by replacing equal amount of distilled water used as a blank. The scavenging activity of the seeds extract was calculated. ${ }^{17,24-25}$

\section{Gas Chromatography-Mass Spectrometry analysis of seeds extract}

A Perkin-Elmer Clarus 600 GC System, fitted with a Rtx-5 MS capillary column with inner diameter of $30 \mathrm{~mm}$ to $0.25 \mathrm{~mm}$ and $0.25 \mu \mathrm{m}$ film thickness withstanding optimal temperature of $350^{\circ} \mathrm{C}$ coupled to a Perkin-Elmer Clarus $60^{\circ} \mathrm{C}$ MS was employed determine the analysis of the extracts from the seeds where the carrier gas used was Ultra-high $99.99 \%$ purity helium maintained at $1.0 \mathrm{~m} /$ minutes constant flow rate. A temperature of $290^{\circ} \mathrm{C}$ were set for the ion source and transfer line injection with the $70 \mathrm{eV}$ ionizing energy. From the auto tune electron multiplier voltage was obtained and the temperature was programmed from $60^{\circ} \mathrm{C}$ with hold for $2 \mathrm{~min}$ to $280^{\circ} \mathrm{C}$ at a rate of $3^{\circ} \mathrm{C} / \mathrm{min}$ for the oven. Using the $1 / 100, v / v$ appropriate solvents the seeds extracts were diluted and filtered and $1 \mu \mathrm{L}$ of theparticle-free diluted extracts were injected into injector with a split ratio 30:1 using a syringe. A obtained data were collected using scan range 40-550 amu from the full scan of mass spectrometry. The presence of components in the extracts were expressed in the form of percentage by the peak area. Based on the Gas Chromatogram retention time the chemical components were characterized and identified. ${ }^{3,13,17-18,24}$

The data from all the performed tests were observed, calibrated and tabulated for the interpretation to study the comparative bioactive chemical composition of the seeds extract of M. oleifera with M. peregrine.
Isolation and Purification of helicobacter pylori

The $H$. pylori bacterium specimen was collected from the endoscopic biopsy gastric juice sample from the patient and immediately transferred to the microbiology laboratory for the process to isolate and purify. The samples were inoculated on the enriched blood culture media, Columbia blood agar media. Agar incorporated with $5 \%$ of sheep's blood and incubated for $24 \mathrm{~h}$ at $37^{\circ} \mathrm{C}$. The appropriate biochemical tests and Gram's staining technique were performed to differentiate $H$. pylori from the other bacterium. ${ }^{9}$ The urea breath test is performed as the one of the significant test for the identification. ${ }^{9}$ The bacterial 16S rRNA sequence expressed using the forward primer sequence: 5 GCT AAG AGA TCA GCC TAT GTC C3 and the reverse one: 5 TGG CAA TCA GCG TCA GGT AAT G3 were identified by using the primers for 500 bp product. The preparation of bacterial genomic DNA was obtained by the vortex by suspending a loopful of isolates in $1 \mathrm{~mL}$ of phosphated-buffer saline (PBS) 7.6 then centrifuged at $14000 \times \mathrm{g}$ for $2 \mathrm{~min}$ and boiling the pellet in $1 \mathrm{~mL}$ of distilled $\mathrm{H}_{2} \mathrm{O}$ for 1 minute. The PCR templates were achieved by centrifuging the samples at $12000 \times \mathrm{g}$ for $4 \mathrm{~min}$ at $4^{\circ} \mathrm{C}$ and the supernatants were stored in sterile vials at $-70^{\circ} \mathrm{C}$. The spectrophotometrical measurement of the bacterial sample was performed at 260 and 280 OD, to verify the concentration and purity to eliminate any possible contamination. The gel electrophoresis for the bacterial sample was performed using $0.8 \%$ agarose.$^{8-9,27}$ The $16 \mathrm{~S}$ rRNA PCR amplification for the $H$. pylori was performed by using the reaction mixture of $25 \mu \mathrm{L}$ with $12.5 \mu \mathrm{L}$ master mix, $0.5 \mu \mathrm{L}$ reverse primer, $6.5 \mu \mathrm{L}$ distilled water and $25 \mu \mathrm{L}$ mineral oil, $5 \mu \mathrm{L}$ DNA samples and $0.5 \mu \mathrm{L}$ forward primer. The parameters employed for the PCR amplification for the $16 \mathrm{~S}$ rRNA of $H$. pylori bacterium were denatured at $95^{\circ} \mathrm{C}$ for 5 min pursued by 39 cycles at $94^{\circ} \mathrm{C}$ for 1 min which was then annealed at $55^{\circ} \mathrm{C}$ for $1 \mathrm{~min}$ and prolonged at $72^{\circ} \mathrm{C}$ for 2 minute. The detection of ureA Gene sequence expressed using the forward primer sequence: 5 GCC AAT GGT AAA GCC TTA GTT3 and the reverse one: 5 CTC CTT AAT TGT TTT TAC 3 for $\mathrm{H}$. pylori along with PCR amplification with a $25 \mu \mathrm{L}$ of reaction mixture containing $12.5 \mu \mathrm{L}$ master mix with $0.5 \mu \mathrm{L}$ forward primer, $5 \mu \mathrm{L}$ DNA samples, $0.5 \mu \mathrm{L}$ reverse primer, $25 \mu \mathrm{L}$ mineral oil and $6.5 \mu \mathrm{L}$ distilled water performed after confirming the presence of $16 \mathrm{~S}$ rRNA by using the primer for 411 bp product of the urea gene. The $2 \%$ agarose was used for the 
electrophoresis. The parameters employed for the PCR amplification for the ureA Gene sequence of $H$. pylori bacterium were denatured at $95^{\circ} \mathrm{C}$ for 5 min pursued by 39 cycles at $94^{\circ} \mathrm{C}$ for 1 min which was then annealed at $55^{\circ} \mathrm{C}$ for $1 \mathrm{~min}$ and extended at $72^{\circ} \mathrm{C}$ for 2 minute..$^{8-9,11-12,27}$

\section{Extraction process of the seed oil extract for Antimicrobial Assay}

The $M$. oleifera and $M$. peregrina seeds were collected and dried. The dried seeds were powdered separately using the mechanical crusher .The hydro-distilled extract of the dried seeds were obtained by preparing homogenized mixture of the dried powder. The concentrate was obtained by filtering with the Whatman number one filter paper which was treated with a pure dinitrogen along with anhydrous sodium sulfate to store at $5^{\circ} \mathrm{C}$ in an amber colored bottles. The moisture content of the dried seed was around $1.84 \mathrm{~g} / 100 \mathrm{~g}$ on a dry basis and seed oil yield in the raw material was approximately $3.866 \mathrm{~mL}$ essential oil/100 $\mathrm{g}$ of dried seeds., ${ }^{3,13-14}$

\section{Antimicrobial efficacy testing}

The antimicrobial efficacy test for the essential oil extract from the seeds against the isolated clinical specimen of $\mathrm{H}$. pylori was performed along with the efficacy of the standard synthetic chemical antibiotics using Kirby-Bauer disc diffusion method $^{3,13,28}$ with the standard Minimum Inhibitory Concentration (MIC) and Minimum Bactericidal Concentration (MBC) techniques to compare the values of efficacy. ${ }^{3,13-15}$ These values tabulated and interpreted to compare the efficacy of seed oil extract from the seeds against the isolated clinical specimen of $H$. pylori with that of the standard synthetic chemical antibiotics. The Kirby-Bauer disc diffusion method was performed by using the Mueller-Hinton agar plates incorporated with $5 \%$ of sheep's blood with the impregnated disc. The antimicrobial discs of the seed oil extract from the seeds were prepared using the Whatman filter paper which were evaluated against the standard antibiotic discs at $37^{\circ} \mathrm{C}$ for $24 \mathrm{~h}$ to observe the zone formation determining the sensitivity of the bacterium towards the disc determining the efficacy by means of different zone diameters. The MIC values along with MBC values for the efficacy antimicrobial activity of the seeds oil extract along with standard antibiotics against the $H$. pylori was evaluated by employing the separate sets of the standard tube dilution method where the isolates were inoculated separately in the different sets of dilutions in the peptone water and incubated at $37^{\circ} \mathrm{C}$ for $24 \mathrm{~h}$ to visualize no turbidity determining the sensitivity of the bacterium. The last dilution with turbidity determines the MIC value. The results were tabulated and interpreted. The MBC was determined by inoculating each dilution of MIC dilutions onto the separate Mueller Hinton agar plates incorporated with $5 \%$ of sheep's blood for each dilutions separately for the seeds oil extracts and the standard antibiotics. The inoculated plates were incubated at $37^{\circ} \mathrm{C}$ for $24 \mathrm{~h}$ to visualize the no growth determining the sensitivity of the bacterium. The first dilution plate with no growth determines the MBC value..$^{3,13-15,28,29}$ The results were tabulated and interpreted.

The standard antibiotics used for the comparative antibiotic assay study with the seed oil extract against $H$. pylori were gentamycin, tetracycline, amoxicillin, metronidazole, ampicillin, kanamycin, rifampin and clarithromycin.

\section{RESULTS AND DISCUSSION}

The antibiotic assay to determine antimicrobial efficacy of the $M$. oleifera and $M$. peregrina seed oil extract shown prominent results against the major gastro-duodenal disease pathogen H. pylorithan that of the standard synthetic chemical antibiotics. ${ }^{9,13-14}$ The bioactive chemical composition of the seeds extract was determined by employing the versatile detailed investigations by performing the Folin-Ciocalteu reagent technique to estimate the TPC, the Aluminum chloride colorimetric technique to estimate the TFC, the DPPH -2,2-diphenyl-1picrylhydrazyl radical technique to estimate the free scavenging radicals, the hydrogen peroxide scavenging assay to evaluate the scavenging activity of the free radicals and the gas chromatographymass spectrometry analysis of seed oils extract investigate the chemical components which were characterized and identified. . $7-18,24-26^{-1}$

The preparation of the ethanol extract from the $M$. oleifera and $M$. peregrina seeds was performed by employing Soxhlet and Kupchan's partitioning technique to derive the extracts of methanol, ethyl acetate, hexane and chloroform by fractionating the crude ethanol extract obtained from the evaporated polar extract at low pressure 
and corresponding fractionated extracts by using evaporation technique in a fuming hood semi solid extracts were obtained by drying the each obtained which were used for the analysis of the bioactive chemical composition of the dried seeds.

The M. oleifera dried seed hexane extract gave the highest yield of $40.85 \%$ followed by methanol extract with $39.15 \%$.The chloroform extract and the ethyl acetate extracts gave reasonable yields of $13.26 \%$ and $6.74 \%$ respectively as described in Figure 1.

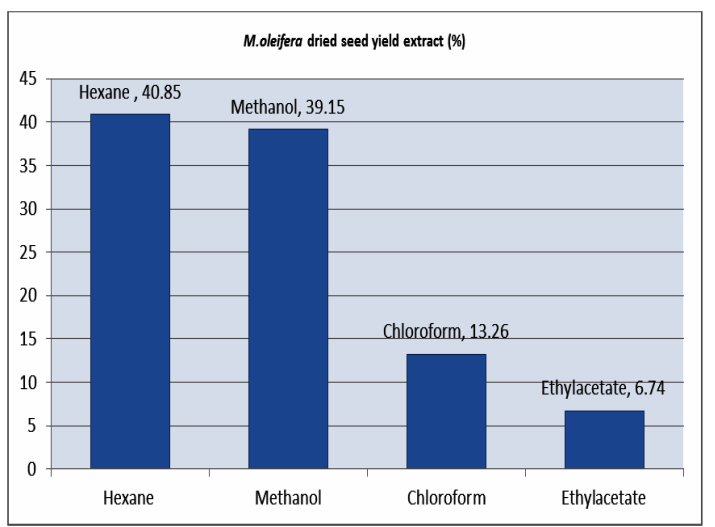

Fig. 1. M. oleifera dried seed yield extract (\%)

The M. peregrina dried seed oil extract also gave the almost same yield with hexane extract gave the highest yield of $41.15 \%$ followed by methanol extract with $40.25 \%$. The chloroform extract and the ethyl acetate extracts gave reasonable yields of $14.50 \%$ and $4.10 \%$ respectively as described in Figure 2 .

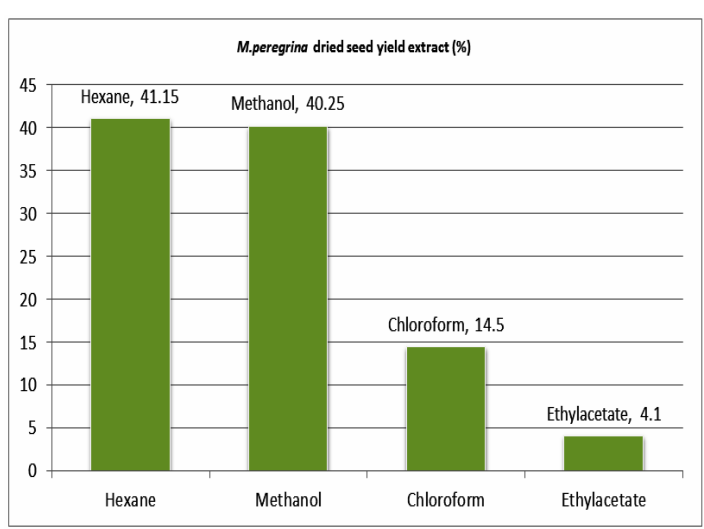

Fig. 2. M. peregrina dried seed yield extract (\%)

The total phenolic content evaluated for the extracts of $M$. oleifera and $M$. peregrina dried seeds shown the presence was more in the methanol extract with $66.76 \%$ and $64.54 \%$ of the total content followed by ethyl acetate content with $23.84 \%$ and
$25.58 \%$ respectively. Though the chloroform extract gave a value of $8.54 \%$ and $8.94 \%$ but the hexane extract gave almost nil values of $0.46 \%$ and $0.94 \%$ respectively. The total phenolic content evaluated for the extracts of $M$. oleifera dried seeds shown the slightly higher values in the methanol extract than that of $M$. peregrina dried seeds where the later shown the slighter higher values in the other extracts. The breakdown of the total phenolic content evaluated for the extracts of $M$. oleifera and $M$. peregrina dried seeds described in Figure 3 and Figure 4.

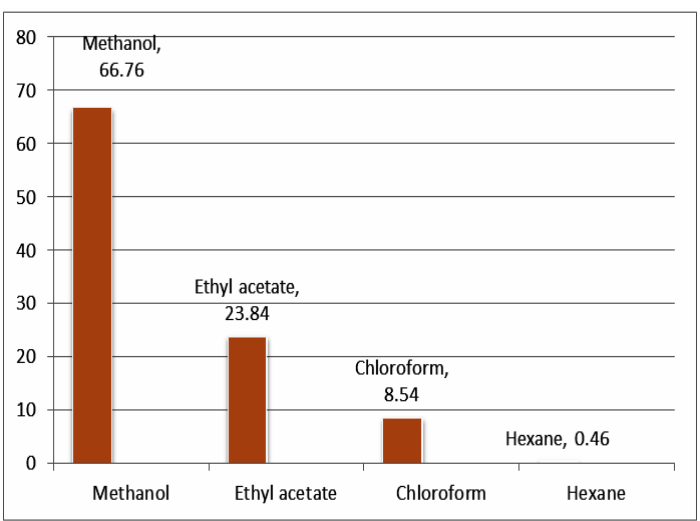

Fig. 3. M. oleifera dried seed TPC (\%)

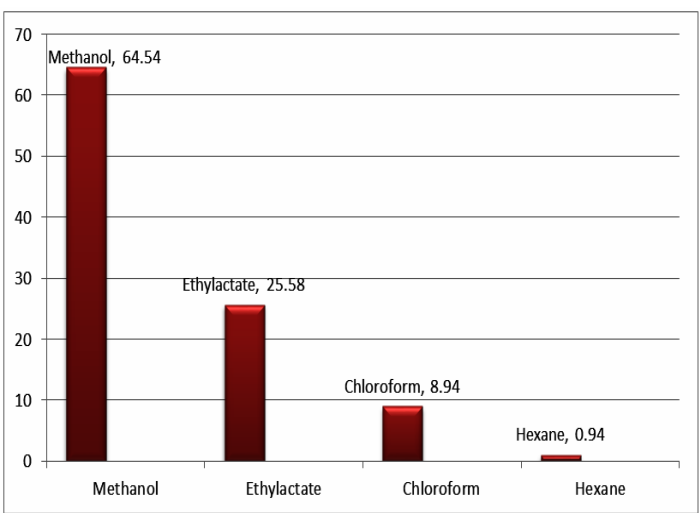

Fig. 4. M. peregrina dried seed yield extract (\%)

The total flavonoid content evaluated for the extracts of $M$. oleifera and $M$. peregrina dried seeds shown almost the same pattern of existence with that of the total phenolic content. The total flavonoid content presence was more in the methanol extract with $56.86 \%$ and $58.54 \%$ of the total content followed by ethyl acetate content with $33.84 \%$ and $31.58 \%$ respectively. Though the chloroform extract gave a value of $7.54 \%$ and $8.14 \%$ but the hexane extract gave the least values of $1.76 \%$ and $1.74 \%$ respectively. The total flavonoid content evaluated 
for the seed oil extracts of $M$. peregrina shown the slightly higher values in the methanol and chloroform extract than that of $M$. peregrina seed oil, where the later shown the slighter higher values in the other extracts. The breakdown of the total flavanoid content evaluated for the seed oil extracts of $M$. oleifera and M. peregrina described in Figure 5 and Figure 6.

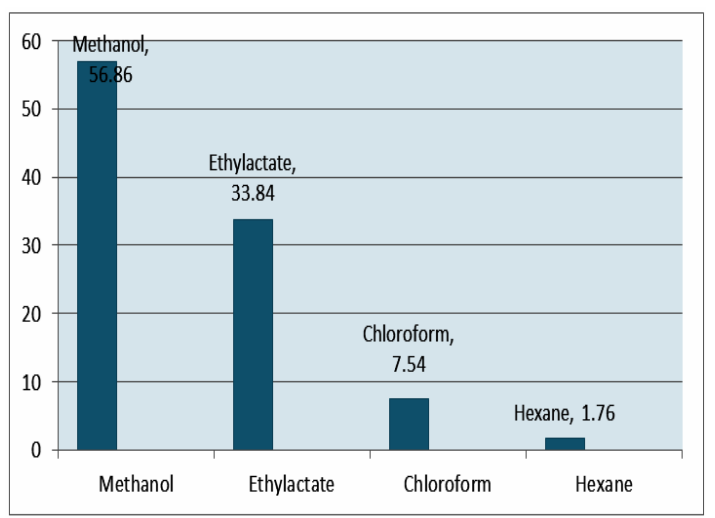

Fig. 5. M. oleifera dried seed TFC (\%)

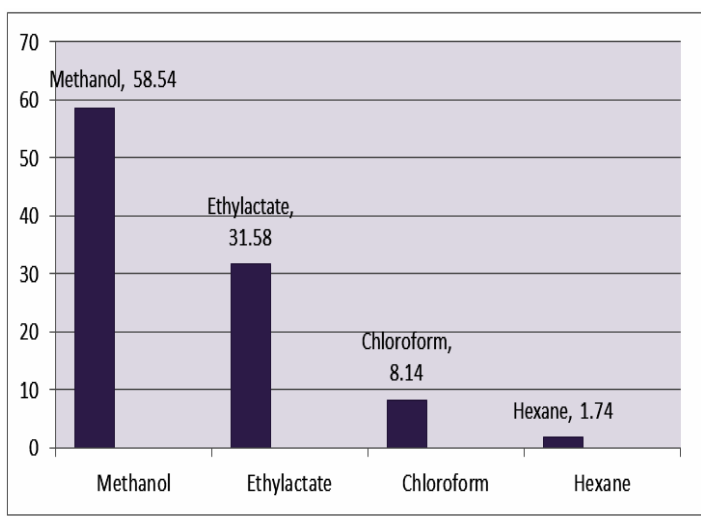

Fig. 6. M. peregrina dried seed TFC (\%)

The estimation of the free scavenging radicals and to evaluate the scavenging activity of the free radical was performed by DPPH-2,2diphenyl-1-picrylhydrazyl radical technique and the hydrogen peroxide scavenging assay respectively for the extracts of $M$. oleifera and $M$. peregrina dried seed oils. The total free radical presence with their scavenging activity was almost same in all the extracts. The methanol extract showed with $26.56 \%$ and $28.54 \%$ of the total content followed by ethyl acetate content with $25.94 \%$ and $24.58 \%$ respectively. The chloroform extract gave a value of $24.94 \%$ and $24.14 \%$ but the hexane extract gave the least values of $22.60 \%$ and $23.90 \%$ respectively. There was not much difference in the estimation of the free scavenging radicals and the scavenging activity of the free radical in all the extracts of both the extracts of the seeds. The breakdown of the total free radicals with their scavenging activity evaluated for the seed oil extracts of $M$. oleifera and $M$. peregrina as described in Figure 7 and Figure 8.

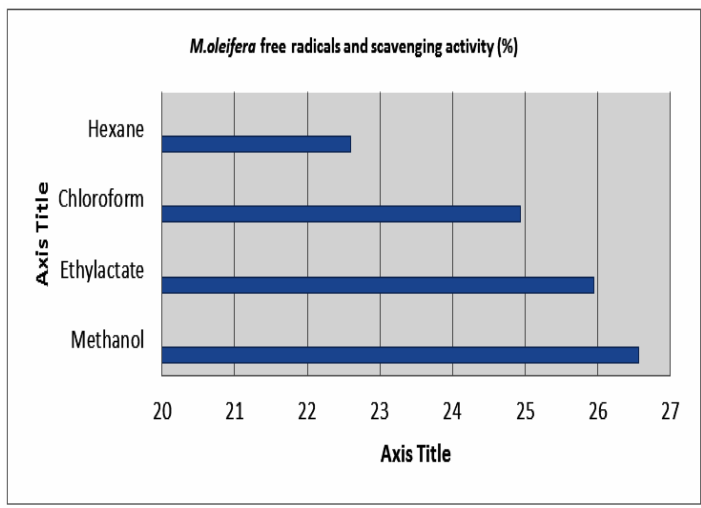

Fig. 7. M. oleifera free radicals and scavenging activity (\%)

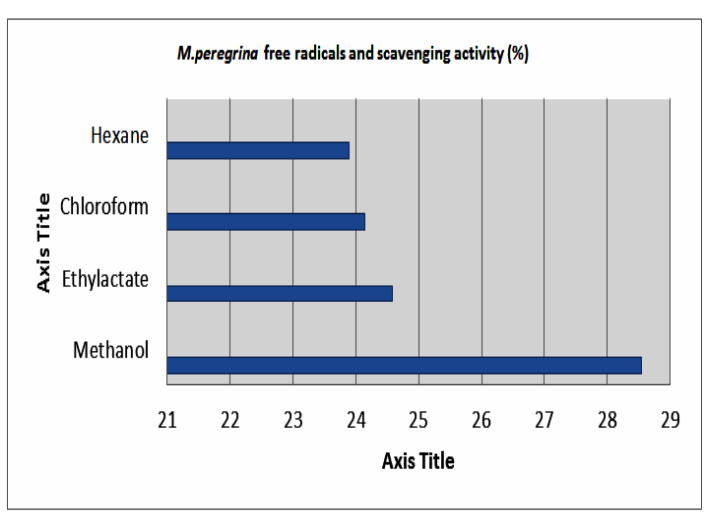

Fig. 8. M. peregrina dried seed yield extract (\%)

The GC-MS analysis of the bioactive components of the extracts of the $M$. oleifera and $M$. peregrina dried seed oils shown the significant data with around thirty plus components related to hydrocarbons, esters, alcohols, fatty acids, ketones, which were determined and characterized in the extracts of ethyl acetate, hexane, methanol and chloroform. These components plays a vital role for their antimicrobial activities especially the phenolic component present in these types of medicinal plants. ${ }^{22-23}$ These components contribute to combat the infectious pathogens as an alternate towards the synthetic chemical antibiotics which results in the evaluation of multi-drug resistant bugs and also causes significant side effects to the human organs. These dried seed oils shown numerous bioactive 
phytochemical components rapport to different classes such as alkaloids, tannins, flavonoids, steroids, glycosides, etc., which can be employed in the phytopharmaceutical industries not only as an antimicrobial agents but also as an anti-oxidant agent. The obtained data of the bioactive chemical composition of the seed oils analyzed by GC-MS was collected and a mean value was prepared from all the extracts and tabulated for the interpretation. The mean value of the obtained Total Phenol Content along with the Total Flavonoid Content and the total free radicals with their scavenging activity evaluated for all the extracts of M. oleiferaand M.peregrina dried seeds were also tabulated with that of GC-MS data in Table 1 for the correlation and interpretation of the results. There were several chromatograms observed through the GC-MS chromatogram for the extracts but most significantly there were around eight similar chromatograms observed for both M. oleifera and M. peregrina dried seed oils which suggests that the chemical composition of both the seed oils were similar with minor difference with extra small chromatogram in the later. Figure 9 and Figure 10.

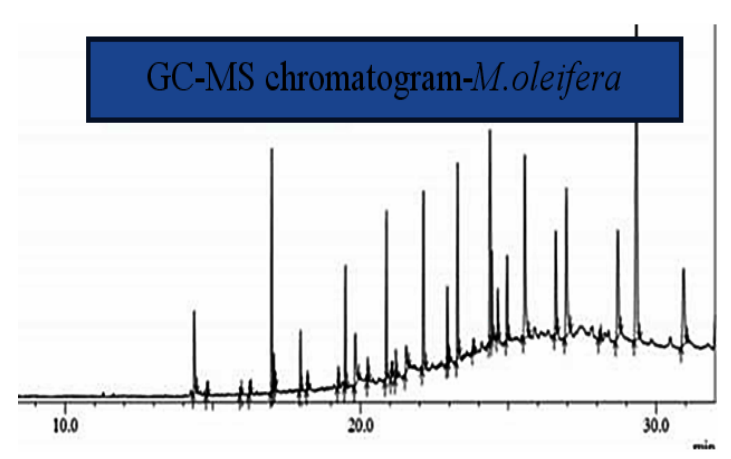

Fig. 9. GC-MS chromatogram (M. oleifera)

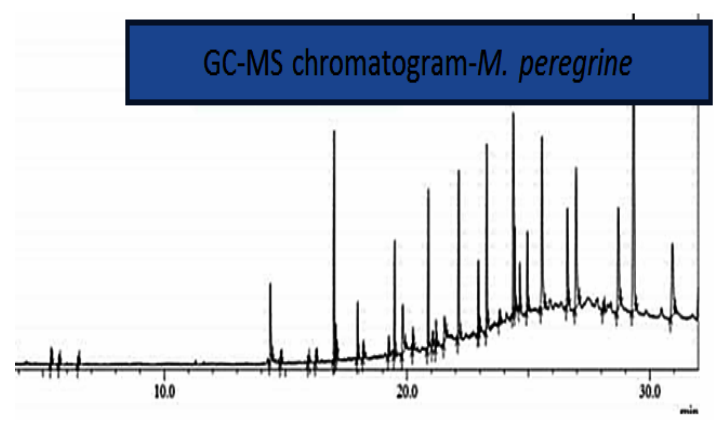

Fig.10. GC-MS chromatogram (M. peregrina)

Table 1: Bioactive chemical composition of the seeds extract analyzed by GC-MS

\begin{tabular}{|c|c|c|c|c|c|c|}
\hline $\begin{array}{l}\text { M. peregrina } \\
\text { seed extract } \\
\text { Retention } \\
\text { Time (min) }\end{array}$ & $\begin{array}{l}\text { M. oleifera } \\
\text { seed extract } \\
\text { Retention } \\
\text { Time (min) }\end{array}$ & $\begin{array}{c}\text { M. peregrina } \\
\text { seed extract } \\
\text { Peak Value (\%) }\end{array}$ & $\begin{array}{c}\text { M. oleifera } \\
\text { seed extract } \\
\text { Peak Value }(\%)\end{array}$ & $\begin{array}{l}\text { M. peregrina } \\
\text { seed extract } \\
\text { content (\%) }\end{array}$ & $\begin{array}{c}\text { M. oleifera } \\
\text { seed extract } \\
\text { content (\%) }\end{array}$ & $\begin{array}{l}\text { Chemical } \\
\text { Components }\end{array}$ \\
\hline 56.6 & 56.4 & 5.06 & 5.02 & 20.10232 & 19.11232 & Pentacosane \\
\hline 56.42 & 57.24 & 4.22 & 4.72 & 14.50775 & 15.57775 & Hexacosane \\
\hline 10.52 & 9.22 & 2.1 & 2.2 & 0.52712 & 2.22712 & C10-hydrocarbon \\
\hline 41.92 & 40.12 & 2.2 & 2 & 2.69259 & 1.89259 & 1-Hexadecanol \\
\hline 58.83 & 55.73 & 4.95 & 4.85 & 15.42913 & 12.02913 & Heptacosane \\
\hline 61.11 & 60.12 & 3.72 & 3.58 & 10.20729 & 8.10729 & Octacosane \\
\hline 4.28 & 5.18 & 3.98 & 3.5 & 11.97442 & 9.67442 & p-Xylene \\
\hline 4.95 & 5.25 & 2.88 & 3 & 2.51735 & 4.81735 & o-Xylene \\
\hline 56.95 & 55.55 & 1.2 & 1.52 & 0.91957 & 2.01957 & Phytol \\
\hline 56.26 & 52.36 & 2.85 & 2.56 & 6.63608 & 3.93608 & Nonacosane \\
\hline 58.69 & 57.59 & 3.56 & 3 & 5.93088 & 3.33088 & Triacontane \\
\hline 3.96 & 4.26 & 1.83 & 0.89 & 2.63553 & 0.33553 & Acetic acid, butyl ester \\
\hline 4.96 & 4.2 & 3.52 & 3.85 & 7.88192 & 9.08192 & Cyclopentanol, 1-methyl- \\
\hline 5.72 & 6.77 & 3.99 & 3.65 & 9.44611 & 8.36111 & 2-Heptanone, 3-methyl- \\
\hline 9.87 & 9.77 & 1.58 & 1.56 & 1.38545 & 1.32945 & Phenyl acetaldehyde \\
\hline 50.76 & 54.26 & 3.83 & 3.75 & 1.95588 & 3.05688 & Hexadecanoic acid, ethyl ester \\
\hline 52.93 & 51.39 & 2.95 & 2.33 & 3.65543 & 1.98543 & 9-Octadecenoic acid ethyl ester \\
\hline 42.64 & 43.46 & 2.03 & 1.85 & 1.99703 & 2.59703 & Heptadecanoic acid, methyl ester \\
\hline 41.29 & 40.92 & 1.26 & 0.89 & 0.97676 & 0.76676 & Nonadecane \\
\hline 39.32 & 39.22 & 0.85 & 0.65 & 0.86105 & 0.63105 & Eicosane \\
\hline 39.75 & 38.35 & 2.44 & 2.36 & 3.88888 & 3.70788 & Heneicosane \\
\hline 6.04 & 5.4 & 3.98 & 3.22 & 3.84387 & 5.76387 & Ethylbenzene \\
\hline 6.2 & 7.8 & 3.78 & 3.66 & 5.69096 & 3.39096 & Hydroperoxide, 1-ethylbutyl \\
\hline 6.6 & 5.06 & 4.25 & 4 & 6.31493 & 4.21493 & Hydroperoxide,1-methylpentyl \\
\hline 6.92 & 7.42 & 9.2 & 8.33 & 26.86481 & 24.26481 & Ethanone, 1-cyclohexyl- \\
\hline 49.5 & 4805 & 7.98 & 7.42 & 14.95281 & 13.45281 & Tetracosane \\
\hline 4.19 & 3.9 & 1.23 & 0.86 & 1.89381 & 0.79381 & Oxirane, 2,2-dimethyl-3-propyl- \\
\hline 53.93 & 54.39 & 3.99 & 3.85 & 7.48510 & 7.06810 & 1-Docosene \\
\hline 48.82 & 46.28 & 7.98 & 7.12 & 15.56480 & 14.79262 & Tricosane \\
\hline 6.8 & 5.36 & 4.85 & 4.1 & 5.21493 & 4.31493 & Squalene \\
\hline 68.82 & 66.28 & 17.98 & 17.12 & 45.86420 & 44.76282 & Total average Flavonoids \\
\hline 69.22 & 69.75 & 19.38 & 19.22 & 58.56420 & 57.56282 & $\begin{array}{c}\text { Total average Phenolic } \\
\text { Compounds }\end{array}$ \\
\hline 62.32 & 65.65 & 23.38 & 21.22 & 78.66420 & 75.45282 & $\begin{array}{l}\text { Total Average DPPH free radical } \\
\text { and } \mathrm{H}_{2} \mathrm{O}_{2} \text { scavenging activity }\end{array}$ \\
\hline
\end{tabular}


The In vitro processing of the collected specimen of endoscopic biopsy gastric juice sample from the patient was performed in the sterile microbiological laboratory for the isolation and purification of $H$. pylori and the test results were tabulated for the correlation and interpretation in the Table 2. The Columbia blood agar supplemented with $5 \%$ of the sheep's red blood cells showed the gamma no hemolytic white colonies. The growth of the bacterium at 0.5 and $0.75 \% \mathrm{NaCl}$ and at 1.00 and $1.25 \% \mathrm{NaCl}$ shown the positive results whereas at $\mathrm{t} 1.5 \% \mathrm{NaCl}$ shown negative results. Similarly negative results were obtained when the bacterium grown at temperature variant at 25,30 and $45^{\circ} \mathrm{C}$ whereas at 35 and $40^{\circ} \mathrm{C}$ the bacterium showed the positive growth results. The catalase test shown the positive results with bubbles formation when a loopful of isolated colonies mixed with a drop of hydrogen peroxide indicating the presence of enzyme catalase splitting $\mathrm{H}_{2} \mathrm{O}_{2}$ into $\mathrm{H}_{2} \mathrm{O}$ and $O$. A loopful of isolated colonies was mixed with the $\mathrm{N}$-Dimethylp-phenylene-diamine (DMPD) resulted in a redox reaction with the development of purple color which indicated the presence of enzyme oxidase. The Gram's staining technique result showed Gram-negative helical curved vibriod bacilli when a loopful of isolated colony was smeared and treated with the Gram's reagents by applying the procedure. A young broth culture was prepared from the isolated colonies of the bacterium to demonstrate the motility by hanging drop technique which showed the Brownian movement over a cavity slide indicating the presence of flagella which suggests that the virulence factor for the disease is by means of flagellar toxins. The glycine tolerance test was negative for the bacterium when the loopful of isolated colony was treated with $1 \%$ of glycine showing no reaction where as the alkaline phosphatase test was positive for the bacterium indicating the presence of the enzyme. The biochemical test results of nitrite reduction and $\mathrm{H}_{2} \mathrm{~S}$ production shown positive results along with the sugar fermentation test of glucose when the loopful of the isolated colonies were inoculated separately in the respective media and incubated overnight at $37^{\circ} \mathrm{C}$. The urea breath test was performed as the confirmatory test to observe the ability of the bacterium to produce the urease enzyme and the result observed was positive with pink color development when the a loopful of colonies were inoculated in the urease media by following the test procedure and incubated overnight at $37^{\circ} \mathrm{C}$. The confirmatory of the obtained results were correlated with that of PCR for the bacterial 16SrRNA sequence vicar by the forward primer sequence: 5 GCT AAG AGA TCA GCC TAT GTC C3 and the reverse one: 5 TGG CAA TCA GCG TCA GGT AAT G3 were identified by using the primers for 500 bp product. The PCR amplification for the detection of ureA Gene sequence vicar by the forward primer sequence: 5 GCC AAT GGT AAA GCC TTA GTT3 and the reverse one: 5 CTC CTT AAT TGT TTT TAC 3 for H. pylori after the confirmation of the presence of $16 S$ rRNA sequence.

Table 2: Isolation and purification of Helicobacter pylori test results

\begin{tabular}{lc}
\hline Tests & Results \\
\hline Gram's staining & Gram-negative vibriods \\
Catalase test & Positive \\
Oxidase test & Positive \\
Glucose fermentation & Positive \\
Urea breath test & Positive \\
Nitrite reduction & Positive \\
H2S production & Positive \\
Hanging drop test & Motile \\
Growth on columbia agar & Gamma non-hemolytic \\
Growth at 0.5 and $0.75 \% \mathrm{NaCl}$ & Positive \\
Growth at 1.00 and $1.25 \% \mathrm{NaCl}$ & Positive \\
Growth at $1.5 \% \mathrm{NaCl}$ & Negative \\
Growth at 25,30 and $45^{\circ} \mathrm{C}$ & Negative \\
Growth at 35 and $40^{\circ} \mathrm{C}$ & Positive \\
$1 \%$ Glycine tolerance test & Negative \\
PCR & 16S rRNA \\
PCR Amplification & UreA \\
\hline
\end{tabular}

Table 3: Antimicrobial efficacy testing comparative chart

\begin{tabular}{|c|c|c|c|}
\hline $\begin{array}{l}\text { Minimum } \\
\text { Bactericidal } \\
\text { Concentration } \mathrm{C} \\
\text { in } \mu / \mathrm{ml}\end{array}$ & $\begin{array}{l}\text { Minimum } \\
\text { Inhibitory } \\
\text { oncentratior } \\
\text { in } \mu / \mathrm{ml}\end{array}$ & $\begin{array}{l}\text { Disc Diffusion } \\
\text { Zone of Inhibition } \\
\text { diameter in mm }\end{array}$ & $\begin{array}{l}\text { Antimicrobial } \\
\text { m Substance }\end{array}$ \\
\hline 0.75 & 0.5 & $\begin{array}{l}\text { Sensitive } \\
28 \\
\text { Sensitive }\end{array}$ & $\begin{array}{l}\text { M. oleifera seed } \\
\text { essential oil extract } \\
\text { M. peregrina seed }\end{array}$ \\
\hline $\begin{array}{l}0.75 \\
1.25\end{array}$ & $\begin{array}{l}0.5 \\
0.75\end{array}$ & $\begin{array}{c}27 \\
\text { Sensitive } \\
23\end{array}$ & $\begin{array}{l}\text { essential oil extract } \\
\text { Gentamycin }\end{array}$ \\
\hline 1.25 & 0.75 & $\begin{array}{l}\text { Sensitive } \\
22\end{array}$ & Tetracycline \\
\hline 1.5 & 1 & $\begin{array}{c}\text { Sensitive } \\
19\end{array}$ & Clarithromycin \\
\hline 1.5 & 1 & $\begin{array}{c}\text { Sensitive } \\
18\end{array}$ & Metronidazole \\
\hline 1.5 & 1.25 & $\begin{array}{c}\text { Sensitive } \\
18\end{array}$ & Kanamycin \\
\hline 1.75 & 1.5 & $\begin{array}{c}\text { Intermediate } \\
\text { Sensitive } \\
12\end{array}$ & Rifampin \\
\hline 1.75 & 1.5 & $\begin{array}{c}\text { Intermediate } \\
\text { Sensitive } \\
10\end{array}$ & Amoxicillin \\
\hline 2 & 1.75 & $\begin{array}{c}\text { Resistant } \\
5\end{array}$ & Ampicillin \\
\hline
\end{tabular}


The determination of the antimicrobial efficacy of the $M$. oleifera and $M$. peregrina dried seed oils were performed by employing the standard microbiological assay techniques of Kirby-Bauer Disc Diffusion method to determine the sensitivity of the bacterium towards the antimicrobial substances by the zone of inhibition diameter in $\mathrm{mm}$ with determining the efficacy of the antimicrobial substance minimal concentration to inhibit and kill the bacteria by performing the MIC in $\mu / \mathrm{ml}$ and MBC in $\mu / \mathrm{ml}$. The antimicrobial assay was performed by using the seed oils which were obtained by the hydro-distilled extract of the dried seeds from the homogenized mixture of the dried powder to determine the efficacy of the $M$. oleifera and $M$. peregrina against $H$. pylori. The antimicrobial discs prepared form the M. oleifera and M. peregrina dried seed oils were compared with that of eight standard antibiotics impregnated in the Mueller-Hinton agar 5\% sheep blood supplemented plates inoculated with the test organism incubated overnight at $37^{\circ} \mathrm{C}$ to observe the zone formation by performing the Kirby-Bauer Disc Diffusion method. A zone of $28 \mathrm{~mm}$ inhibition was observed with $M$. oleifera seed oil and a zone of $27 \mathrm{~mm}$ inhibition was observed with $M$. peregrina seed oil extract indicating an excellent sensitivity. The best sensitivity for the standard antibiotics was observed with a zone of $23 \mathrm{~mm}$ for gentamycin, $22 \mathrm{~mm}$ for tetracycline, $19 \mathrm{~mm}$ with clarithromycin, $18 \mathrm{~mm}$ for both metronidazole and kanamycin. The intermediate sensitivity was observed with a zone of $12 \mathrm{~mm}$ for rifampin and $10 \mathrm{~mm}$ with amoxicillin where as the bacterium showed resistance towards ampicillin with just a zone of $5 \mathrm{~mm}$ diameter. The MIC and MBC results for $M$. oleifera and $M$. peregrina seed oils compared with that of standard antibiotics where in line with the disc diffusion test results. The MIC values of the seed oils extract were 0.5 to $0.75 \mu / \mathrm{mL}$ concentration with the MBC values of 0.75 to $1 \mu / \mathrm{mL}$ concentration. The standard antibiotics gentamycin and tetracycline showed MIC values of 0.75 to $1 \mu / m L$ concentration and MBC values of 1.25 to $1.5 \mu / \mathrm{mL}$ concentration. The MIC values of clarithromycin, metronidazole, kanamycin were 1.25 to $1.5 \mu / \mathrm{mL}$ concentration with $\mathrm{MBC}$ values of 1.5 to $1.75 \mu / \mathrm{mL}$ concentration. The standard antibiotics rifampin and amoxicillin showed the MIC values of 1.5 to $1.75 \mu / \mathrm{mL}$ concentration and MBC values of 1.75 to $2 \mu / \mathrm{mL}$ concentration. Finally, the standard antibiotic Ampicillin showed disappointing results with MIC and MBC values of 1.75 to $2 \mu / \mathrm{mL}$ concentration and 2 to $2.25 \mu / \mathrm{mL}$ concentration respectively. The results were tabulated in Table 3 for the correlation and interpretation along with a detailed chart Fig.11. The obtained results from the performed antibiotic assay to determine the potential efficacy of the seed oils prepared from the dried seeds of the $M$. oleifera and $M$. peregrina showed that both phyto-antimicrobial substances exhibit better sensitivity with minimal concentration required to inhibit or kill the $H$. pylori bacterium to combat the gastro-duodenal diseases than that of the standard chemical antibiotics with higher concentrations. The presence of vital chemical components in the seed oils especially phenolic compound contributes to its antimicrobial activity.

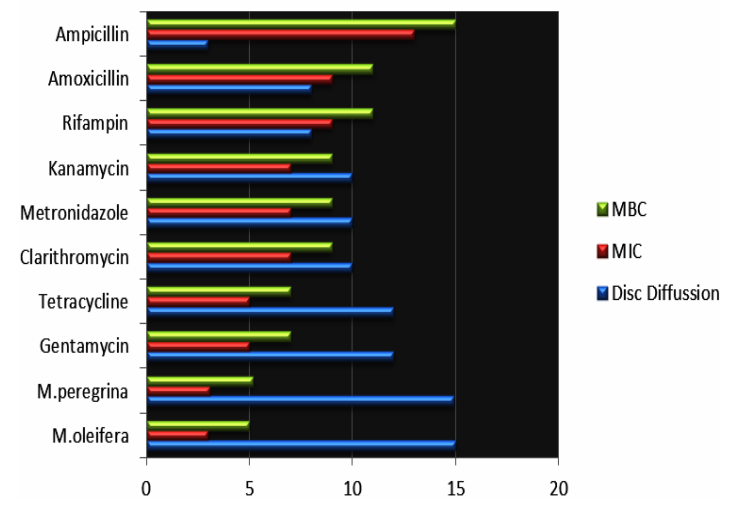

Fig. 11. Antimicrobial efficacy testing comparative chart

\section{CONCLUSION}

The rise of gastro-intestinal infectious diseases in recent times has alarmed the WHO, as there are limited antibiotics which can cure these disorders, especially caused by H. pylori. Furthermore, these chemical based antibiotics are associated with many adverse effects as well as increased incidence of multi-drug resistant strains of microorganisms. Hence, the WHO has recommended the evaluation of novel phytochemicals for treatment of various diseases. This has led to an increase in demand of research on plant based nutraceutical products. This investigation is a small effort to resurrect the ancient phyto-pharmaceutical substances to treat such infections by comparing the antimicrobial efficacy along with bioactive composition analysis of the dried seed oils of $M$. oleifera from Indian origin and M. peregrina from Egyptian origin. The bioactive composition for both the seed oils showed almost same composition with little variance. A total of thirty bioactive components were identified from the seeds 
by employing GC-MS analysis and the presence of phenolic compound which is the vital element for the antimicrobial efficacy of the seeds along with other phyto-chemical substances. ${ }^{18,30-31}$ The antimicrobial efficacy of the seed oils revealed that the sensitivity of the bacterium towards both the seed oils was excellent when compared to that of the eight standard chemical antibiotics. The minimal concentration value of these seeds showed promising results to inhibit or completely eradicate the bacterium when compared to the values of the eight standard chemical antibiotics. Thus, this study suggests that more studies need to be conducted to discover the nature blessed available remedies to combat the microbial infections rather than be dependent on the chemical compounds.

\section{ACKNOWLEDGEMENT}

We would like to acknowledge Ibn Sina National College and Al Jedaani Hospital, Jeddah, Kingdom of Saudi Arabia.

\section{Conflict of interest}

No conflict of interest.

\section{REFERENCES}

1. Hulten K.; Han SW.; Enroth H.; Klein PD.;Opekun AR.; Gilman RH.; Evans DG.; Engstrand L.; Graham DY.; El-Zatari FA., Helicobacter pylori in the drinking water in Peru. Gastroenterology., 1996, 110(4), 1031-1035.

2. Benson JA.; Fode-Vaughan KA.; Collins MLP., Detection of Helicobacter pylori in water by direct PCR. Letters in Applied Microbiology., 2004, 39(3), 221-225.

3. Muazzam SM.; AlHasel HMB.; Majid DH.; Momen TN.; AlHazmi HAM.; AlJeddani FMS.; AIMalaki RTW.; Khan AA.; Iqubal, SMS., Chemical Analysis (GC-FID-MS) and Antimicrobial Activity of Parmotrema perlatum Essential Oil Against Clinical Specimens. Orient . J. Chem., 2019, 35(6), 1695-1701.

4. Azevedo NF.; Almeida C.; Cerqueira L.; Dias S.; Keevil CW., Vieira MJ., Coccoid form of Helicobacter pylori as a morphological manifestation of cell adaptation to the environment. Applied and Environmental Microbiology., 2007, 73(10), 3423-3427.

5. Al-Sulami AA.; Al-Kiat HS.; Bakker LK.; Hunoon $\mathrm{H}$., Primary isolation and detection of Helicobacter pylori from dyspeptic patients: a simple, rapid method. Eastern Mediterranean Health Journal., 2008, 14(2), 268-275.

6. Agha-Amiri K.; Peitz U.; Mainz D.; Kahl S.; Leodolter A.; Malfertheiner P., A novel immunoassay based on monoclonal antibodies for the detection of Helicobacter pylori antigens in human stool. Z. Gastroenterol., 2001, 39, 555-560.

7. Necchi V.; Candusso ME.; Tava F.; Luinetti O.; Ventura U.; Fiocca R.; Ricci V.; Solcia E., Intracellular, intercellular, and stromal invasion of gastric mucosa, preneoplastic lesions, and cancer by Helicobacter pylori. Gastroenterology., 2007, 132(3), 1009-1023.

8. H. Liu H.; Rahman A.; Semino-Mora S.; Doi SQ.; A. Dubois A., Specific and sensitive detection of $\mathrm{H}$. pylori in biological specimens by real-time RT-PCR and in situ hybridization PLoS ONE., 2008, 3(7), Article ID e2689.

9. Francis; Me'graud ; Philippe; Lehours, clinical microbiology reviews, American Society for Microbiology. INSERM U853, F33076 Bordeaux, France, and Universite Victor Segalen Bordeaux 2, Laboratoire de Bacte'riologie, F33076 Bordeaux, France. 2007, 20(2), 280-322.

10. Al-Sulami AA.; Al-Taee AMR.; Juma'a MG., Isolation and identification of helicobacter pylorifrom drinking water in Basra governorate, Iraq. Eastern Mediterranean Health Journal., 2010, 16(9), 810-816.

11. Agha A.; Opekun AR.; Abudayyeh S.; GrahamY., Effect of different organic acids (citric, malic and ascorbic) on intragastric urease activity. Aliment. Pharmacol. Ther., 2005, 21, 1145-1148.

12. Adachi K.; Kawamura A.; Ono M.; Masuzaki K.; Takashima T.; Yuki M.; Fujishiro H.; Ishihara S.; Kinoshita Y., Comparative evaluation of urinebased and other minimally invasive methods for the diagnosis of helicobacter pylori infection. J. Gastroenterol., 2002, 37, 703-708.

13. Muazzam SM.; Khan AA.; Tasneem M.; Iqubal SMS.; Shaikh IA.; Muddapur UM.; Sheik GB.; Singh SK.; Hussain MS.; Gamal, M., Determination of Antioxidant Properties and Antimicrobial activity of vinyl phenolic compounds extracted from saccharomyces cerevisiae against uropathogenic bacteria. Orient. J. Chem., 2020, 36(1), 26-32. 
14. Muazzam SM.; Khan AA.; Iqubal SMS.; Tasneem M.; Shaikh IA.; Dawoud A.; Muddapur UM.; Hussain MS.; Singh SK., Comparison of e-test Values for Standard Antibiotics and Conventional Antimicrobial Assay Values for Ethanoic Acids against Nosocomial Multidrug resistant Pseudomonas aeruginosa. J. Pure Appl. Microbiol., 2020, 14(1), 255-260.

15. Bisht CMS.; Iqubal SMS.; Khan AA.; Tasneem M.; Dawoud A.; Gamal M.; Singh SK., Asghar $\mathrm{BH}$., Natural Products in Drug Discovery: Antibacterial and Antifungal Activity of Essential oil of Compound Isolated from Senecio royleanus. J. Pure Appl. Microbio., 2019, 13(3), 1611-17.

16. Motsumi PT.; Qwebani-Ogunleye T.; Ejidike IP.; Mtunzi FM.; Nate Z., Teedia lucida root extracts by ultrasonication and maceration techniques: Phytochemical screening, antimicrobial and antioxidant activity. Rasayan Journal Chemistry., 2020, 13(1), 423-433.

17. Khumalo BM.; Qwebani-Ogunleye T.; Ejidike IP.; Mtunzi FM.; Pinkoane M., Evaluation of immune booster formulation by traditional health practitioners: Phytochemical, antioxidant and mineral elements studies. International Journal of Pharma and Bio sciences., 2018, 9(2), 29-37.

18. Makanyane DM.; Ejidike IP.; Ssemakalu CS.; Mtunzi FM.; Pakade VE.; Klink MJ.; Lebelo RS., GC-MS analysis and extraction optimization of bioactive compounds from Pelargonium graveolens LHér methanolic extract and their activities as pharmacological agents. International Research Journal of Pharmacy., 2019, 10(9), 59-72.

19. Khan AA.; Iqubal SMS.; Shaikh IA.; Niyonzima FN.; More VS.; Muddapur UM.; Bennur RS.; More SS., Biotransformation of Longifolene by Penicillium europium, Biocatalysis and Biotransformation, 2020, Accepted.

20. Abdel-RahmanTahany MA.; Hegazy AK.; Sayed AM.; Kabiel HF.; El- Alfy T.; El-Komy SM., Study on combined antimicrobial activity of some biologically active constituents from wild Moringa peregrina Forssk. J. Yeast Fungal Res., 2010, 1(1), 15-24 (2010).

21. El-Batran SA.; Abdel-Salam OM.; Abdelshfeek KA.; Nazif NM.; Ismail SI.; Hammouda FM., Phytochemical and pharmacological investigation on Moringa peregrine (Forssk) Fiori. Nat. Prod. Sci., 2005, 11(4), 199- 206.

22. Chauke MA.; Shai LJ.; Mogale MA.; Tshisikhawe MP.; Mokgotho MP., Medicinal plant use of villagers in the Mopani district,
Limpopo province, South Africa. Afr. J. Trad. Complement. Altern. Med., 2015, 12, 9-26.

23. Chikezie PC.; Ibegbulem CO.; Mbagwu FN., Bioactive principles from medicinal plants. Res. J. Phytochem., 2015, 9, 88-115.

24. Bagewadi ZK.; Muddapur UM.; Madiwal SS.; Mulla SI .; Khan AA., Biochemical and enzyme inhibitory attributes of methanolic leaf extract of Datura inoxia Mill. Environmental Sustainability., 2019, 2, 75-87.

25. Salma Jamalian; Christina Truemper; Elke Pawelzik, Jasmonic an Abscisic Acid Contribute to Metabolism Re-adjustment in Strawberry Leaves under $\mathrm{NaCl}$ Stress. International Journal of Fruit Science., 2019, 112, 1-22.

26. Muhit MA.; Tareq SM.; Apu AS.; Basak D.; Islam MS., Isolation and identification of compounds from the leaf extract of Dillenia indica Linn. Bangladesh Pharm. J., 2010, 13(1), 49-53.

27. Alarcon T.; Domingo.; Prieto N.; Lopez Brea M., PCR using 3 -mismatched primers to detect $\mathrm{A} 2142 \mathrm{C}$ mutation in 23S rRNA conferring resistance to clarithromycin in Helicobacter pylori clinical isolates. J. Clin. Microbiol., 2000, 38, 923-92.

28. Gouse, BS.; Muazzam, SM., Gokul S.S.; Ranjith, M.S., Isolation and characterization of actinomycetes from soil of ad-dawadmi, Saudi Arabia and screening their antibacterial activities. Int. J. of Pharm. and Pharmaceutical Sc., 2017, 9(10), 267-79.

29. Muazzam SM.; Yumna AB.; Samaher GB.; Shaden NA.; Bashair MMO.; Khan AA.; Iqubal SMS.; Tasneem M., A Comparative Study of Different Types of Thyme Essential oils Against Streptococcus pyogenes to Determine their Biochemical and Antimicrobial Properties. Orient. J. Chem., 2020, 36(2), 220-228.

30. Mtunzi FM.; Ejidike IP.; Matamela T.; Dikio ED.; Klink MJ., Phytochemical profiling, antioxidant and antibacterial activities of leaf extracts from Rhus leptodictya. Int. J. Pharmacognosy and Phytochem.Res., 2017, 9, 1090-1099.

31. Lokesh T.; Sarada B.; Swarnalatha K.; Kareem MA.; Varadacharyulu NCH., Antihaemolytic activity of phytochemical aqueous extracts of Pterocarpus santalinus and Phyllanthus emblica in red blood cells of human subjects receiving chronic alcohol and cigarette smoking. Int. J. Pharm. Sci. Res., 2016, 7, 3857-3864. 